\title{
Influence of Heat Control on Residual Stresses in Low Transformation Temperature (LTT) Large Scale Welds
}

\author{
Jonny Dixneit, ${ }^{1,{ }^{*}}$, Arne Kromm, b, Mirko Boin ${ }^{2, c}$, Thomas Kannengiesser ${ }^{1, d}$ and \\ Jens Gibmeier ${ }^{3, \text { e }}$ \\ ${ }^{1}$ Bundesanstalt für Materialforschung und -prüfung (BAM), Unter den Eichen 87, 12205 Berlin, \\ Germany \\ ${ }^{2}$ Helmholtz-Zentrum Berlin für Materialien und Energie $\mathrm{GmbH}$, Hahn-Meitner-Platz 1, 14109 \\ Berlin, Germany \\ ${ }^{3}$ Karlsruhe Institute of Technology, IAM, Engelbert-Arnold-Straße 4, 76131 Karlsruhe, Germany \\ ajonny.dixneit@bam.de, barne.kromm@bam.de, 'boin@helmholtz-berlin.de, \\ dhomas.kannengiesser@bam.de, ejens.gibmeier@kit.edu
}

\begin{abstract}
Keywords: LTT, Welding Residual Stress, Phase Transformation, Interpass Temperature.
\end{abstract}

\begin{abstract}
The current paper presents residual stress analyses of large scale LTT (Low Transformation Temperature) welds. LTT filler materials are specially designed for residual stress engineering by means of an adjusted martensite phase transformation. Controlling the level of mostly detrimental residual stresses already during the welding process would be highly attractive as time and cost consuming post processing may be prevented. In large scale welds the residual stress state is influenced by the heat control (e.g. interpass temperature) during welding. Therefore, welding residual stresses are studied here putting the focus on the influence of welding process parameters while joining heavy steel sections with a thickness of $25 \mathrm{~mm}$. The residual stress state was determined at the top surface using X-ray diffraction as well as in the bulk by neutron diffraction. The results show that control of the interpass temperature is vital for the residual stresses present in the joints. This accounts for the top surface but is most pronounced for the bulk of the welds. While high interpass temperatures are appropriate to induce compressive residual stresses in the weld metal, low interpass temperatures favor unwanted tensile residual stresses instead.
\end{abstract}

\section{Introduction}

Despite the well-known benefit of post-weld heat treatments on fatigue life due to altering welding residual stresses, such processes often lead to additional production costs. Novel Low Transformation Temperature (LTT-) filler materials are specially designed for controlling weld residual stresses by means of an adjusted martensite formation already during welding and thus its application may minimize costs. The volume expansion due to phase transformation counteracts the contraction due to shrinkage of the joint. Tensile residual stresses are reduced or even beneficial compressive residual stresses are formed. The strength of these filler materials makes them potentially applicable to high-strength steels as well as to repair works in existing steel structures. The influence of varying phase transformation temperatures on the residual stresses for different weld geometries was the aim of most investigations up to now. Shiga et al. [1] and Francis et al. [2] confirmed that compressive residual stresses can be achieved, when welding LTT-alloys with varying martensit start $\left(\mathrm{M}_{\mathrm{S}^{-}}\right)$temperatures. The focus was also on the influence of the welding parameters. High interpass temperatures can delay the martensite formation during multi-pass welding. It follows that the whole weld metal undergoes the phase transformation not before cooling to ambient temperature after deposition of the last bead. On the other hand, low interpass temperatures allow repeated martensite formation in the already deposited layers. Both alters the 
residual stresses found in a welded joint [3]. But the final residual stresses are also influenced by the restraint conditions of the structure. That means the weld is restrained by the adjacent base material (BM) as well as by the stiffness of the whole weld construction. Zenitani et al. [4] already confirmed the influence of varying restraint intensities regarding residual stresses in LTT-joints. Therefore, the present study was focused on the evaluation of the residual stresses in thick walled LTT-joints showing a high restraint concerning the impact of the interpass temperature.

\section{Experimental}

Materials and Welding. Based on already published chemical compositions two LTT alloys were prepared. Some characteristics are presented in Table 2 and Table 1. Both fillers show the main alloying elements chromium and nickel or manganese respectively. Two different interpass temperatures were applied. Butt welding was carried out in eleven runs by Pulsed Gas Metals Arc Welding (P-GMAW) using LTT flux cored wires. The weld samples $(250 \mathrm{~mm} \times 200 \mathrm{~mm})$ exhibit a thickness of $25 \mathrm{~mm}$ each and were prepared with an opening angle of $45^{\circ}$. The high strength steel S960QL was used as a base material. The specimens were heated to preheat temperature using a furnace. Preheat and interpass temperatures were controlled by thermocouples on various positions in the heat affected zone (HAZ). The welding parameters are shown in Table 3.

Table 1: chemical composition of the base and filler material ( $\left.f_{c w}\right)$

\begin{tabular}{|l|c|c|c|c|c|c|c|c|c|}
\hline \multicolumn{2}{|l|}{ Chemical composition (wt.-\%), *measured on pure (weld-) samples using dilatometry tests } & \multirow{2}{*}{$\mathrm{M}_{\mathrm{S}}{ }^{*}$} \\
\hline base material & $\mathrm{C}$ & $\mathrm{Si}$ & $\mathrm{Mn}$ & $\mathrm{Cr}$ & $\mathrm{Ni}$ & $\mathrm{Mo}$ & $\mathrm{B}$ & $\mathrm{Fe}$ & $\left({ }^{\circ} \mathrm{C}\right)$ \\
\hline LTT CrNi & 0.17 & 0.29 & 0.82 & 0.51 & 0.91 & 0.51 & 0.0002 & $\mathrm{Bal}$ & 419 \\
& & & & & & & & \\
\hline
\end{tabular}

Table 2: mechanical properties of base and filler materials

\begin{tabular}{|c|c|c|c|}
\hline & $\mathrm{R}_{\mathrm{p} 0,2}$ in $\mathrm{MPa}$ & $\mathrm{R}_{\mathrm{m}}$ in MPa & reference \\
\hline base material & 985 & 1018 & - \\
\hline LTT CrNi & 900 & 1123 & \multirow{2}{*}[5]{} \\
\hline LTT CrMn & - & 1074 & \\
\hline
\end{tabular}

Table 3: welding parameters

\begin{tabular}{|c|c|}
\hline wire diameter & $1.6 \mathrm{~mm}$ \\
\hline arc voltage (RMS value) & $29 \mathrm{~V}$ \\
\hline welding current (RMS value) & $377 \mathrm{~A}$ \\
\hline welding speed & $520 \mathrm{~mm} / \mathrm{min}$ \\
\hline preheat- and interpass temperature & $50{ }^{\circ} \mathrm{C}$ and $200{ }^{\circ} \mathrm{C}$ \\
\hline $\mathrm{t}_{8 / 5}$-time (averaged), & $7 \mathrm{~s}$ and $11 \mathrm{~s}$ \\
\hline shielding gas & $\mathrm{M} 13,1 \% \mathrm{O}_{2}$ \\
\hline
\end{tabular}

X-ray diffraction. The residual stress measurement was carried out midways on the top surface of the samples using the $\sin ^{2} \psi$ technique [6]. Residual stresses were determined in longitudinal as well as in tranverse direction of the weld line using the parameters shown in Table 4.

Table 4: measuring and evaluation parameter for $X$-ray diffraction

\begin{tabular}{|c|c|}
\hline Measuring position & weld, HAZ, BM (top surface, midway) \\
\hline radiation & $\mathrm{CrK}_{\alpha}$ \\
\hline X-ray spot size & $2 \mathrm{~mm}$ \\
\hline Exposure time & $5 \mathrm{~s}$ \\
\hline
\end{tabular}




\begin{tabular}{|c|c|}
\hline$\Psi$-range & $0 \ldots \pm 45^{\circ}$ in 7 steps \\
\hline Diffraction line & ferrite/martensite: 211 \\
\hline$E\{211\}$ & $220.000 \mathrm{MPa}$ \\
\hline$v\{211\}$ & 0.28 \\
\hline
\end{tabular}

Neutron diffraction. Stress measurements were performed at the instrument E3 at the BERII facility of the HZB Berlin, Germany [7]. The setup is shown in Fig. 1 (left). As a multi-axial stress state was expected in the welded joints, strain measurements were necessary in the three principle directions covering the longitudinal, transversal and weld depth direction (normal). Using a neutron wavelength of approximately $0.147 \mathrm{~nm}$ the $\alpha / \alpha^{\prime}-\mathrm{Fe}\{211\}$ diffraction peak located at approximately $2 \Theta=78^{\circ}$ was utilized for strain measurement. The exposure time varied between $10 \mathrm{~min}$ to $30 \mathrm{~min}$. From lattice strains in principle directions the stresses were calculated. A gauge volume of $2 \times 2 \times 2 \mathrm{~mm}^{3}$ was chosen for the transversal as well as weld depth direction while in longitudinal direction the gauge volume was adapted to $2 \times 2 \times 10 \mathrm{~mm}^{3}$ to achieve a sufficient spatial resolution and acceptable exposure time. The measuring positions were realized midway along the specimens. Three measuring lines in distances of 4, 12.5 and $21 \mathrm{~mm}$ to the plate surface were chosen as indicated in Fig. 1 (right). The measuring range included in total 15 measuring points located in the weld and on both sides of the HAZ, while the BM was covered single sided only. Weld distortion was not balanced for the measuring lines. As the LTT weld metals are higher alloyed compared to the base material the unstrained lattice parameter $a_{0}$ was determined from appropriate reference specimens. For this purpose a thin comb was cut from each sample representing the weld cross section including the $\mathrm{HAZ}$ and BM. The prongs of the comb were prepared by Electrical Discharge Machining to reduce thermal effects to the material.
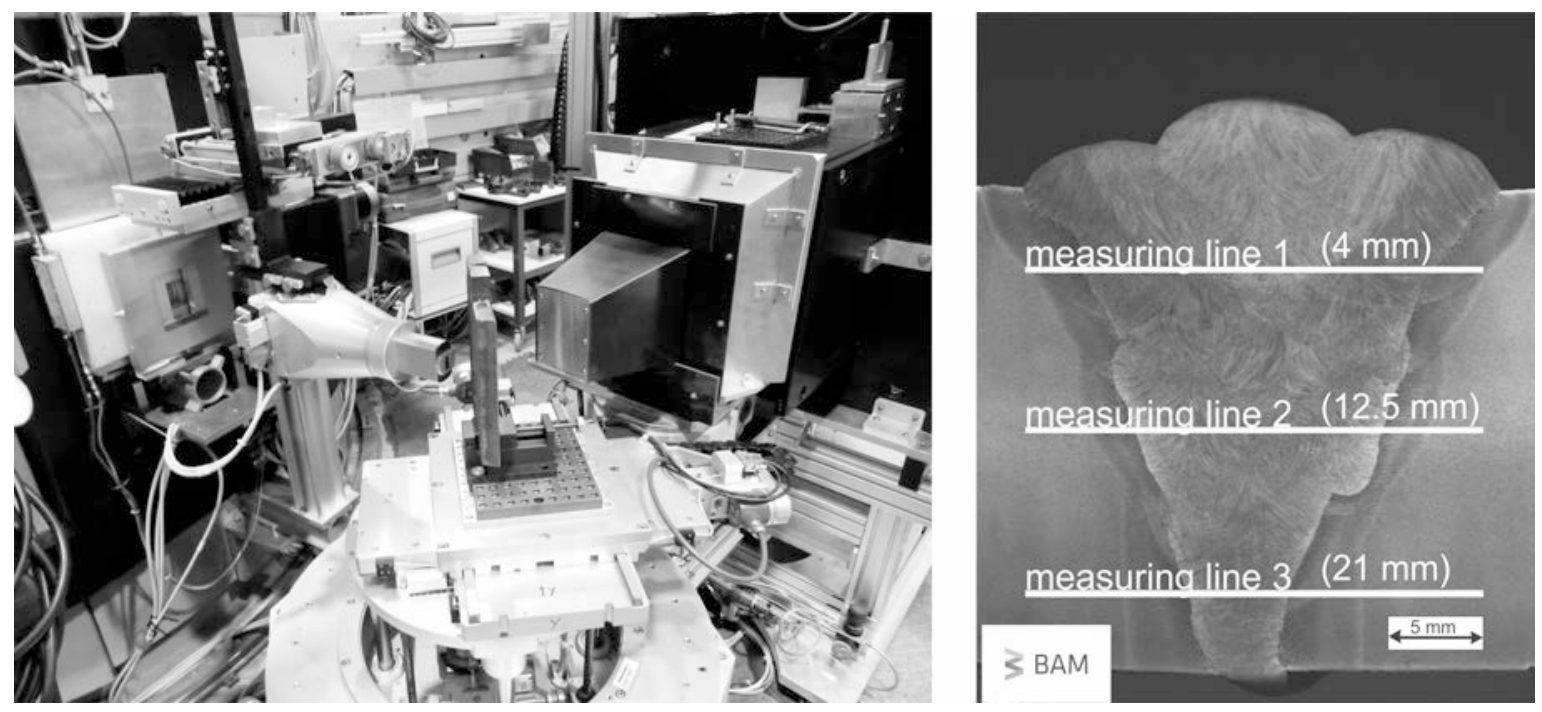

Fig. 1: setup of the neutron diffraction experiment at the instrumentE3@BER II (left) and assignment of the measuring lines to the joints cross section (right)

\section{Results and Discussion}

Residual Stresses - Surface. Residual Stresses found in the surface of the welds are presented in Fig. 2 and Fig. 3. The longitudinal stress distribution of all joints is quite similar in quality. Moreover, the residual stress level in the LTT CrMn welds is almost identical except for a single tensile peak value in the left hand side weld metal at the lower interpass temperature. In case of the $\mathrm{CrNi}$ filler the residual stress level is slightly decreased when applying the higher interpass temperature. In this case the weld is characterized mainly by comparatively low tensile residual stresses up to about $300 \mathrm{MPa}$, while the lower interpass temperature shows peak values around 
$500 \mathrm{MPa}$. These stress levels are also to be found in the HAZ. In any case the transition to the BM shows a steep residual stress gradient. In this area the stresses change from tension into compression. Adjacent to the HAZ the residual stresses are decreased to compressive values between $-200 \mathrm{MPa}$ and $-300 \mathrm{MPa}$ given by the BM condition before welding (sand blasted). Some high measurement errors are due to microstructural reasons.
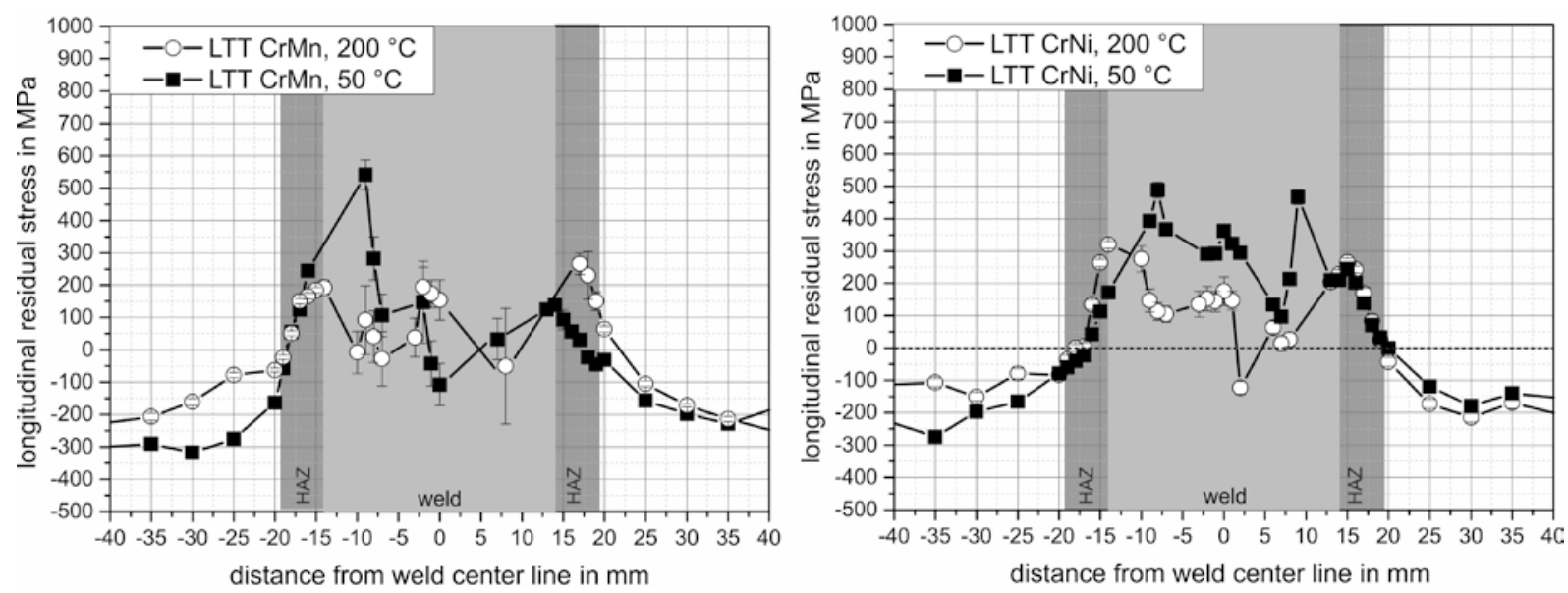

Fig. 2: surface longitudinal welding residual stresses for the CrMn-filler (left) and the CrNifiller (right) induced during welding using different interpass temperatures

In contrast there are some differences to be observed in transversal direction. The weld metals are in tension up to about $800 \mathrm{MPa}$ and the region showing tensile residual stresses is wider when using the high interpass temperature. Additionally, the residual stresses exhibit several maxima in the weld center. On the other hand, with lower interpass temperature single stress peaks appear in the center without dips. The HAZ shows low compressive residual stresses on the level of the BM up to about $-300 \mathrm{MPa}$. Independent from the interpass temperature applied the longitudinal residual stresses are lower than the transverse ones. This is consistent to results found in other LTT joints [8]. Higher interpass temperatures lead to slightly decreased stress levels in longitudinal direction. But in transversal direction the high tensile residual stresses are limited to a smaller zone in the weld metal center in case of lower interpass temperatures.
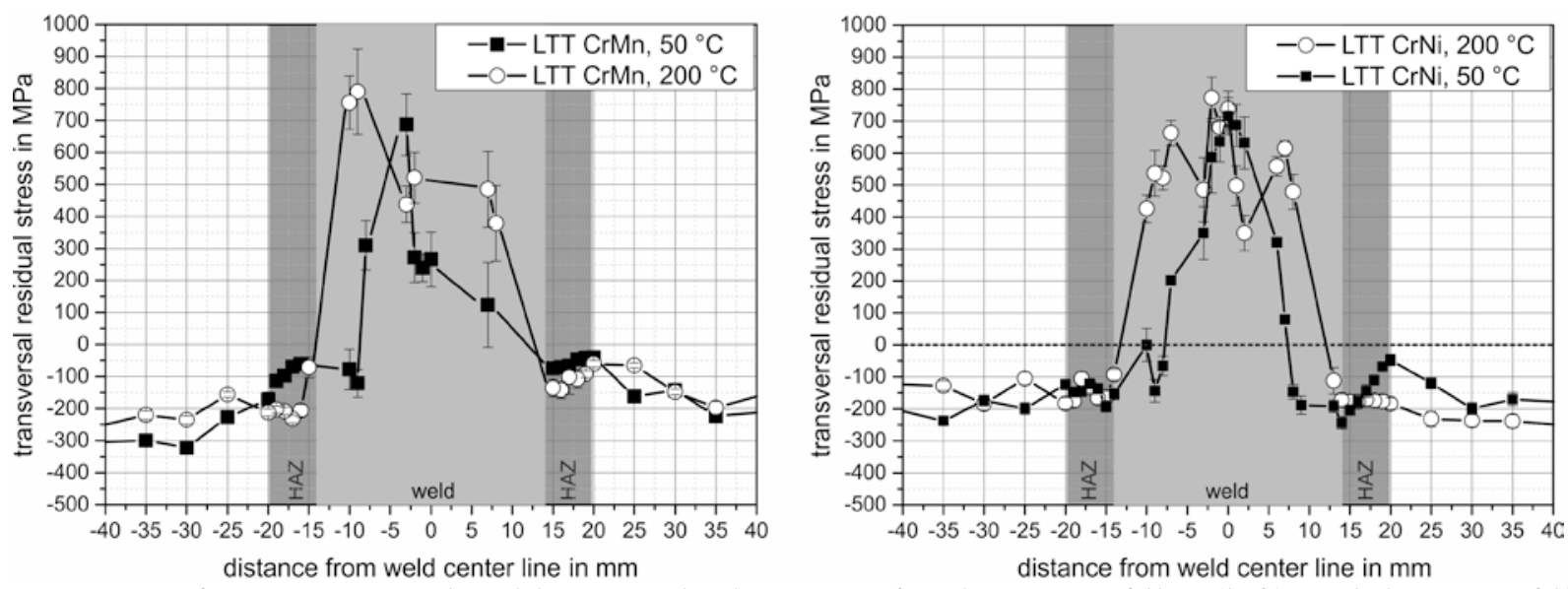

Fig. 3: surface transversal welding residual stresses for the CrMn-filler (left) and the CrNi-filler (right) induced during welding using different interpass temperatures 
Residual Stresses - Bulk. Longitudinal as well as transversal residual stresses are shown for the LTT CrNi in Fig. 4. The LTT CrMn exhibits the similar residual stress distributions in quality and is therefore not shown. In case of an interpass temperature of $200^{\circ} \mathrm{C}$ there are compressive longitudinal stresses detectable through the bulk. They are lost in case of the root (Fig. 1 line 3), where tensile stresses balance up to about $380 \mathrm{MPa}$ in the weld metal. Similar to the top surface high tensile stresses are present in the HAZ independent from the depth. The stress magnitudes are higher than on the surface (max. $700 \mathrm{MPa}$ ). Also contrary to the surface in transversal direction there are quite low tensile residual stresses of up to about $350 \mathrm{MPa}$ detectable in the weld metal only. The HAZ varies between tension and compression from $4000 \mathrm{MPa}$ to $-300 \mathrm{MPa}$. In case of an interpass temperature of $50{ }^{\circ} \mathrm{C}$ the longitudinal stress level is shifted completely into tension reaching the level of the surface stresses. Longitudinal stress peaks are also detectable through the material bulk in the HAZ up to $900 \mathrm{MPa}$. In transversal direction the welding residual stress distribution is less affected by lower interpass temperatures. The stress level shows low tensile stress up to $400 \mathrm{MPa}$ in the weld and $430 \mathrm{MPa}$ in the HAZ. High tensile stress levels as found at the surface are not detectable. In the normal direction the stress distribution of the LTT alloys is comparable to the transversal welding residual stresses and therefore not shown.
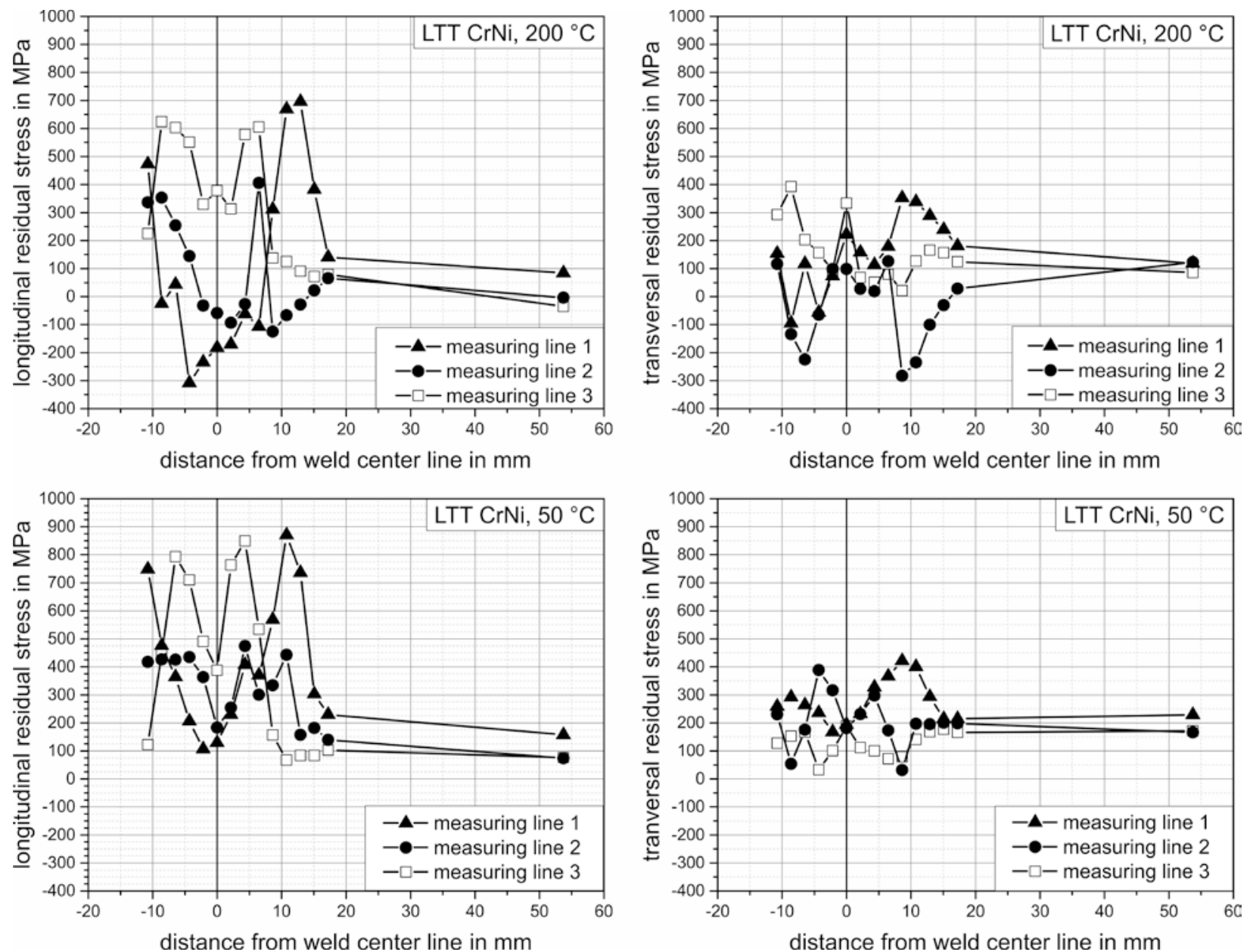

Fig. 4: residual stress in bulk for the LTT CrNi, interpass temperature $200{ }^{\circ} \mathrm{C}$ (above) and $50{ }^{\circ} \mathrm{C}$ (below)

\section{Summary and Conclusions}

The present work dealt with the residual stresses in high strength heavy plate joints welded with LTT fillers applying different interpass temperatures. The residual stresses were determined using X-ray 
(surface residual stresses) and neutron diffraction (bulk residual stresses). The following conclusions can be drawn:

- Independent from the interpass temperature residual stresses in longitudinal direction are lower than in transverse direction. This applies for the surface as well as for the bulk of the welds.

- Welding residual stresses in the bulk are lower compared to stresses found on the surface.

- Compressive residual stresses as a result of the martensite formation are determined in the bulk weld metal, only.

- Independent from the LTT filler used high interpass temperatures are beneficial to reduce the stresses mainly in longitudinal direction.

- Lower interpass temperatures tend to narrow the tensile zone in the weld metal but they also prevent the formation of compressive residual stresses.

\section{Acknowledgements}

The authors would like to especially acknowledge the German Research Foundation (DFG) for funding parts of this work (KA 1807/4-1 | GI 376/4-1), Lincoln Electric Europe for provision of welding consumables as well as EWM AG for support.

\section{References}

[1] C. Shiga; H.Y. Yasuda; K. Hiraoka; H. Suzuki: Effect of Ms Temperature on Residual Stress in Welded Joints of High-Strength Steels. Welding in the World, Vol. 54 (2010), No. 3-4, pp. R71-R79

[2] J.A. Francis; S. Kundu; H.K.D.H. Bhadeshia; H.J. Stone; R.B. Rogge; P.J. Withers; L. Karlsson: The Effects of Filler Metal Transformation Temperature on Residual Stresses in a High Strength Steel Weld Intervening Transformations. Journal of Pressure Vessel Technology vol. 131 (2009), pp. 1-15. https://doi.org/10.1115/1.3122036

[3] H. Dai; R.J. Moat; P.J. Withers: Modelling the Interpass Temperature Effect on Residual Stress in Low Transformation Temperature Stainless Steel Welds. In: ASME 2011 Pressure Vessels and Piping Conference: Volume 6, Parts A and B, ASME, 2011, pp. 1451-1458. https://doi.org/10.1115/pvp2011-57329

[4] S. Zenitani; N. Hayakawa; J. Yamamoto; K. Hiraoka; Y. Morikage; T. Kubo; K. Yasuda; K. Amano: Development of new low transformation temperature welding consumable to prevent cold cracking in high strength steel welds. Science and Technology of Welding and Joining, Vol. 12 (2007), No. 6, pp. 516-522

[5] S. Vanrostenberghe, M. Clarin, Y. Shin, B. Droesbeke, V. Van der Mee, M. Doré, G. Marquis, J. Parantainen, T. Kannengießer ZB (2015) Improving the fatigue life of high strength steel welded structures by post weld treatments and specific filler material. doi: 10.2777/705266

[6] P. Müller, E. Macherauch: Das $\sin ^{2} \psi$-Verfahren der röntgenographischen Spannungsmessung*. Zeitschrift für angewandte Physik. Vol. 13 (1961), pp. 306-312 [in german]

[7] T. Poeste, R. C. Wimpory, R. Schneider: The new and upgraded neutron instruments for material science at HMI - current activities in cooperation with industry. Materials Science Forum, Vol. 524-525 (2006), pp. 223-228. https://doi.org/10.4028/www.scientific.net/MSF.524-525.223

[8] A. Kromm; T. Kannengiesser; J. Altenkirch; J. Gibmeier: Residual Stresses in Multilayer Welds with Different Martensitic Transformation Temperatures Analyzed by High-Energy Synchrotron Diffraction. Materials Science Forum, Vol. 681 (2011), pp. 37-42. https://doi.org/10.4028/www.scientific.net/MSF.681.37 